\title{
A comprehensive techno-economic and power quality analysis of a remote PV-diesel system in Australia
}

\author{
Taskin Jamal ${ }^{*}$, G.M. Shafiullah, Craig Carter, and Tania Urmee \\ School of Engineering and Information Technology, Murdoch University, Australia
}

Received: 16 January 2017 / Received in final form: 7 July 2017 / Accepted: 27 July 2017

\begin{abstract}
Presently, the world is considering the integration of small, medium and large-scale PV systems into both urban and remote rural electricity networks. This sees a transition towards a $100 \%$ renewable energy based electricity supply from the current conventional fossil fuel based electricity supply. Australia has a significant electricity generation potential from solar PV resources which also encourages the uptake of PV-battery hybrid systems. Australian utilities operating in the isolated and remote areas are now seriously considering the integration of solar PV systems as a long-term solution to reduce costs and facilitate sustainable electricity generation. This would also defer expensive grid extension to supply electricity to these dispersed remote communities. This study aims to model and optimise a remote Australian PV-diesel system incorporated with high levels of PV penetration and battery storage and investigate the system power quality issues. The study includes system component optimisation and techno-economic analysis which considers the outcomes regarding the cost of energy (AUD $\$ / \mathrm{kWh}$ ), fuel savings potential and environmental impacts. Power quality issues have been explored by analysing the response of fast frequency-responsive (FFR) battery storage. The overall study has found that higher levels of $\mathrm{PV}$ penetration integrated with the current diesel operated system provides a comprehensive and efficient electricity supply and FFR Li-ion batteries can mitigate transient power quality issues and maintain system frequency within acceptable limits.
\end{abstract}

\section{Introduction}

Hundreds of millions of the world population live in remote rural areas where extending the electricity grid is not practical due mainly to the geographic location, load and customer density and the cost of implementation and maintenance. These off-grid isolated areas are supplied by small sized stand-alone electricity supply systems, usually employing diesel generation and now solar PV (resembling an islanded microgrid). Australia has many such isolated systems in its vast geographical area. The community and industry loads of these regions are mainly supplied by diesel and/or natural gas. Due to the abundant solar resource and the decreasing cost of PV systems, Australian electricity distribution network service providers (DNSP) operating diesel systems are highly motivated and interested in reducing the loading and dispatch of fossil fuel based generators with small, medium and largescale PV power generation and are providing incentives for this. For example, Horizon Power (HP), a remote area state-owned DNSP in the state of Western Australia

\footnotetext{
* e-mail: t.jamal@murdoch.edu.au
}

(WA) offers renewable energy buyback rates (feed-in tariff) for its customers, currently ranging from AUD 7.14 cents $/ \mathrm{kWh}$ in Broome and Exmouth to AUD 51.41 cents $/ \mathrm{kWh}$ in Menzies [1]. The upfront costs of PV systems are still quite high, considering living standard in remote area communities. Hence, the system design has to be cost efficient, as well technically robust, to encourage more uptake of PV systems. When substantial energy storage facilities are added to a PV-diesel hybrid system, PV generation with battery backup provides reliable power and the system stability improves. Batteries are common energy storage devices, used in PV-diesel systems worldwide. These systems are usually weak in configuration compared to robust urban networks. Hence, the variable power output of PV systems has a significant impact on the generation portfolio and when integrated into these remote diesel systems, the DNSP face critical decision-making situations to maintain the supply quality, stability and reliability. Poor and unplanned PV-battery integration may cause deterioration of power quality, increased system complexities in network operation and management [2-5]. Some of the major technical issues deterring higher levels of PV penetration are: power quality - voltage regulation and 


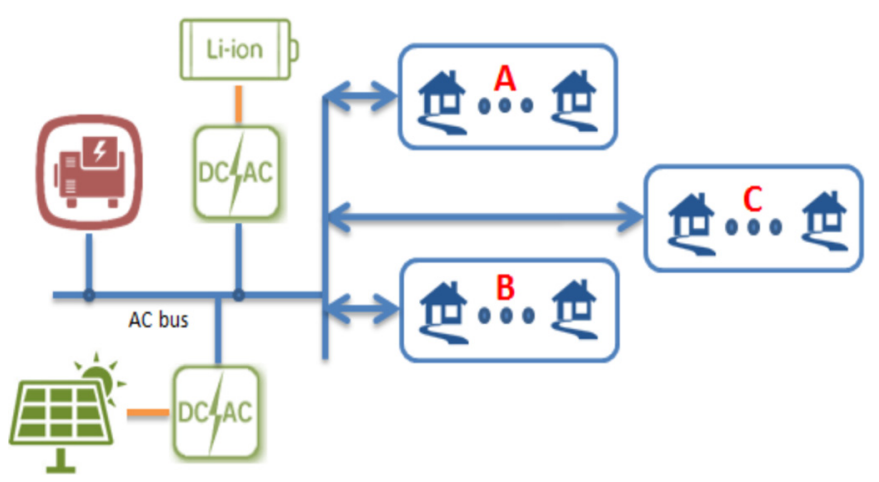

Fig. 1. Scenario-1: centralised PV and battery bank scheme.

frequency deviation [3,6,7], ramp rates of conventional generators $[5,8,9]$ and spinning reserve shortage and dynamics $[3,5]$. As PV systems lack mechanical inertia and do not include any local governor, it becomes difficult for PV-diesel systems to provide adequate control of system frequency and thus maintain system stability. The key challenges of integrating higher levels of $\mathrm{PV}$ penetration into PV-diesel systems are closely associated with providing sufficient network stability and spinning reserve and managing power quality. Fast response battery storage systems can facilitate the network tackling with transient power quality related issues, caused by the variable PV power output characteristic. Fast response Li-ion batteries are now widely used due to their higher energy density, extended cycle life and fast charging characteristics.

In a previous research study, an Australian PV-diesel system integrated with a centralised PV-battery installation was analysed and it was concluded that the PVdiesel-battery configuration provides a techno-economic comprehensive solution [7]. The analysis presented in this article is the continuation of the previous study. The optimal design configuration of the same system is presented in this study, which also investigates the system power quality during varying net load conditions. Two approaches have been proposed for the demonstration: the first one is the centralised approach (scenario-1) and the other is the semi-distributed approach (scenario2 ). The first part of the analysis is to perform a system optimisation for both the scenarios using Hybrid Optimisation of Multiple Energy Resources (HOMER) Pro software. The second part contains an investigation of the system's power quality using DIgSILENT PowerFactory software, based on the results obtained from the first part. Section 2 presents the PV-diesel system overview. Findings from the first part analysis are discussed in Section 3 and Section 4 presents the findings from the second part. Section 5 concludes the overall results of the study.

\section{System overview and model}

A Western Australian remote PV-diesel system from the Mid-West region, operated by HP is considered for this analysis. The schematic diagrams of both the scenarios

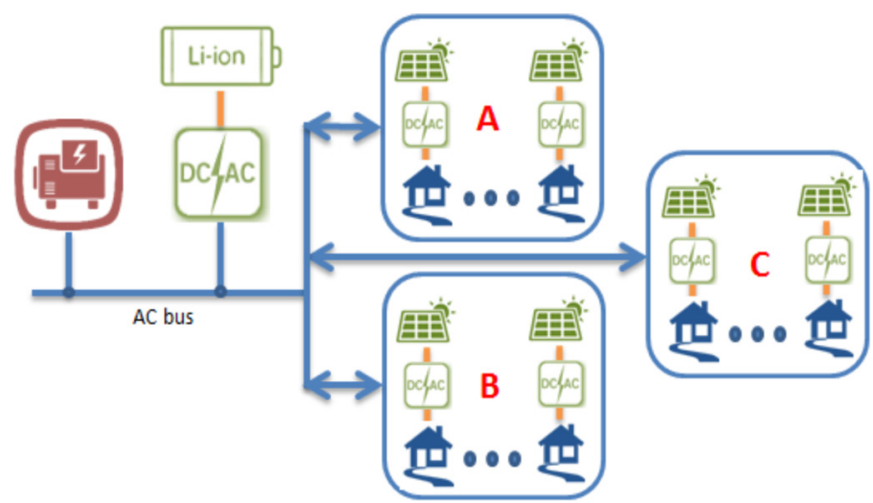

Fig. 2. Scenario-2: distributed PV and centralised battery bank scheme.

mentioned earlier are presented in Figures 1 and 2. The system has a total installed diesel generation capacity of $875 \mathrm{kVA}$ to supply an annual peak load of $589 \mathrm{~kW}$. The network has five identical diesel generators (DG), each having a maximum capacity of $170 \mathrm{kVA}$ which are connected to $0.415 \mathrm{kV}$ generation busbar. There are three distribution feeders: both $\mathrm{A}$ and $\mathrm{B}$ feeders having a peak load of $115 \mathrm{~kW}$ and $\mathrm{C}$ feeder, a peak load of $350 \mathrm{~kW}$ (Fig. 1). The step-down distribution transformers for both $\mathrm{A}$ and $\mathrm{B}$ are connected through $5 \mathrm{~km}$ overhead lines, whereas the same transformer for $\mathrm{C}$ is $15 \mathrm{~km}$ away from the generator side step-up transformer. In the centralised approach (Fig. 1), the grid-tied inverter coupled PV systems are connected to the $0.415 \mathrm{kV}$ generation busbar, whereas in the semi-distributed approach (Fig. 2), they are connected to individual feeders. For convenience, distributed PV systems are considered as lumped. The PV systems consist of flat plate PV panels have a temperature coefficient of -0.5 and conversion efficiency of $13.5 \%$. A panel derating factor of $90 \%$, the ground reflectance of $20 \%$ and a lifetime of 20 years have been considered. A $6 \mathrm{~V}, 1 \mathrm{kWh}$ Li-ion battery model has been used to create a $24 \mathrm{~V}$ dc bus. In both the scenarios, the battery bank is connected to the generation busbar. The battery model that has been used is an idealized battery model, that assumes a flat discharge curve considering the voltage remains mostly constant during the discharge cycle. Some significant specifications of the $1 \mathrm{kWh}$ Li-ion battery are - nominal capacity: $167 \mathrm{Ah}$, roundtrip efficiency: 90\%, maximum charge current: $167 \mathrm{~A}$, maximum discharge current: $500 \mathrm{~A}$ and minimum state of the charge: $30 \%$. The identical generators possess same manufacturing specifications. Minimum lifetime of a generator is considered as $60,000 \mathrm{~h}$. Minimum load ratio and minimum run time have been considered as $40 \%$ and $30 \mathrm{~min}$, respectively. The fuel curve intercept coefficient is $0.0194 \mathrm{~L} / \mathrm{h} / \mathrm{kW}$-rated and the slope is $0.222 \mathrm{~L} / \mathrm{h} / \mathrm{kW}$ output. The bi-directional battery converter considers inverter efficiency of $98 \%$ and rectifier efficiency of $96 \%$. The efficiency of grid-tied PV-inverters is $96 \%$.

As more and more PV systems are integrated, the operational strategies of the network are highly influenced by the integration pattern of PV systems and battery 
Q3 Table 1. Comparative analysis of two scenarios.

\begin{tabular}{|c|c|c|}
\hline & Scenario-1 [7] & Scenario-2 \\
\hline \multicolumn{3}{|l|}{ Fuel usage status } \\
\hline & $14.30 \%^{*}$ (only with PV) & $23.50 \%{ }^{*}$ (SR includes $100 \%$ of PV) \\
\hline Fuel savings potential & $\begin{array}{l}14.90 \% \%^{*} \text { (incl. battery, SR of } 100 \% \text { of PV) } \\
20 \%^{*} \text { (incl. battery, SR of } 25 \% \text { of PV) }\end{array}$ & $25.80 \%^{*}$ (SR includes $25 \%$ of PV) \\
\hline \multicolumn{3}{|l|}{ System status } \\
\hline Annual energy supply & $2,406,784 \mathrm{kWh}$ & $2,406,784 \mathrm{kWh}$ \\
\hline Total DG capacity & $700 \mathrm{~kW}$ & $700 \mathrm{~kW}$ \\
\hline $\mathrm{PV}$ rated capacity & $289.17 \mathrm{~kW}$ & PV_A and PV_B each: $100 \mathrm{~kW}, \mathrm{PV} \_\mathrm{C}: 174 \mathrm{~kW}$ \\
\hline System PV penetration & $23.66 \%^{* *}\left(\right.$ or $\left.49.24 \%^{* * *}\right)$ & $29 . \overline{33} \%^{* *}\left(\right.$ or $\left.63.5 \%^{* * *}\right)$ \\
\hline Inverter capacity & $\begin{array}{l}250 \mathrm{~kW} \text { (grid-tied) } \\
16 \mathrm{~kW} \text { (bi-directional) } \\
16-32 \mathrm{kWh} \text { Li-ion }\end{array}$ & $\begin{array}{l}\mathrm{PV} \_\mathrm{A} \text { and PV_B: } 70 \mathrm{~kW}, \mathrm{PV} \_\mathrm{C}: 140 \mathrm{~kW} \\
200 \mathrm{~kW} \text { (bi-directional for battery) } \\
100 \mathrm{kWh} \text { Li-ion }\end{array}$ \\
\hline Battery size & $\begin{array}{l}\text { ( } 4-8 \text { nos. of strings, } 4 \text { nos. } 1 \mathrm{kWh} \\
\text { battery/string) }\end{array}$ & ( 25 nos. of strings, 4 nos. $1 \mathrm{kWh}$ battery/string) \\
\hline $\begin{array}{l}\text { Emission status } \\
\text { Reduction of } \mathrm{CO}_{x} \\
\text { Cost status }\end{array}$ & $218 \mathrm{t} /$ year & $359 \mathrm{t} /$ year \\
\hline COE $(\mathrm{AUD} \$ / \mathrm{kWh})$ & $\begin{array}{l}0.349 \text { (without battery) } \\
0.318-0.346 \text { (with battery) }\end{array}$ & $\begin{array}{l}0.303 \text { (with battery) } \\
0.361 \text { (reference) }\end{array}$ \\
\hline
\end{tabular}

\footnotetext{
* Compared with the reference case.

** PV annual energy penetration level.

*** PV peak power penetration level.
}

banks. The electricity generation philosophy considered in this network is to maximise the PV penetration satisfying all technical constraints at the lowest life-cycle cost.

\section{System optimisation and techno-economic analysis}

HOMER microgrid modelling tool is used to conduct the techno-economic simulation, optimisation and sensitivity analysis of the hybrid system. In this analysis, both scenarios are simulated and optimised in HOMER Pro, which assists the decision making of component ratings and the understanding of the system's behaviour. During the optimisation process, different system configurations are simulated to find out the best outline that satisfies all the technical constraints at the lowest life-cycle cost $[10,11]$.

\subsection{Optimisation problem formulation, dispatch controller}

The first part of the analysis optimises the size of system components, such as DGs, PV systems, batteries and inverters. The system components and market price information to solve the optimisation problem have been taken from the previous study. The analysis reference scenario, where the DGs are only allocated for electricity generation, is built on the system configuration presented in that study. As PV-battery systems are integrated into the reference case, the system economic dispatch can be formulated as:

$$
\begin{aligned}
& \text { Minimize }\left[O M C\left(P_{g i}, P V_{i}, B, S R\right)\right], \\
& \text { Minimize }\left[F\left(P_{g i}\right)\right] \\
& \text { Minimize }[\text { Excess Electricity }] \text { and } \\
& \text { Maximize } \sum_{i=}^{N} P V_{i} \\
& \text { Subject to } \\
& L(t)=S R(t)=P(t) \\
& \sum_{i=2}^{M} P_{g i}+\sum_{i=1}^{N} P V_{i}+\sum B \geq L(t) \\
& \gamma L(t)+\sigma P V_{i}=S R(t) \\
& P_{g i}^{\text {min }} \leq P_{g i} \leq P_{g i}^{\text {rated }} \\
& P_{g i}^{\text {min }} \geq \alpha P_{g i}^{\max } \\
& S O C^{\text {min }} \leq S O C(t) \leq S O C^{\max } \\
& t_{P_{g i}^{\min } \geq 30 \min }
\end{aligned}
$$

Here, $O M C=$ combined operation and maintenance costs of conventional generators, PV systems, battery bank and spinning reserve; $F=$ fuel usage; $P_{g i}=$ power generation from the $i$ th conventional generator; $P V_{i}=$ power generation from the $i$ th PV system; $B=$ battery bank capacity; $S R=$ spinning reserve; $P(t)=$ power generation capacity at any time " $l$ "; $L(t)=$ load plus losses at any time " $t$ "; $S R(t)=$ spinning reserve at any time " $t$ "; $\gamma=$ percentage of the load at any time " $t$ "; $\sigma=$ percentage of $\mathrm{PV}$ output at any 

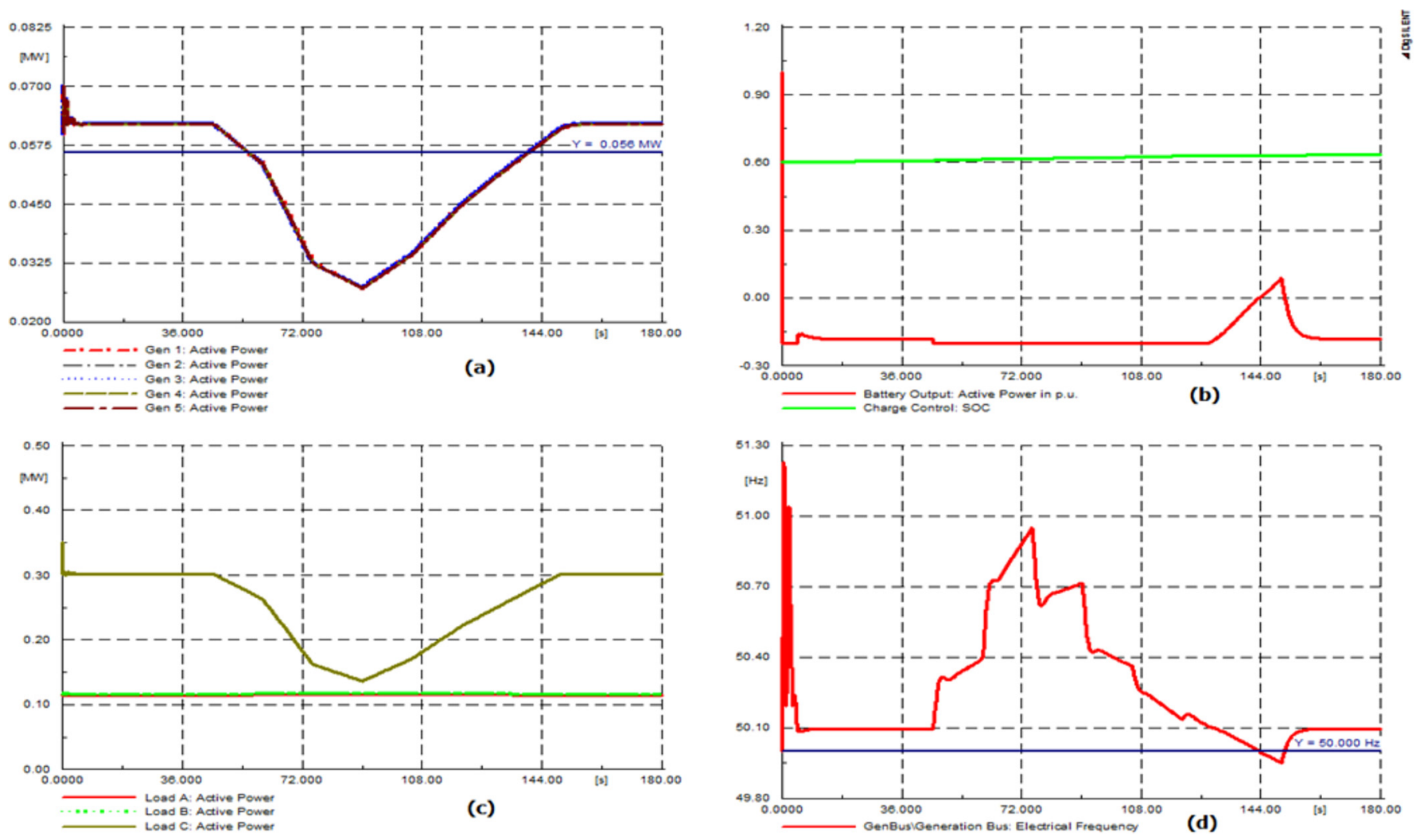

Fig. 3. Case 1 for scenario-1.

time " $t$ "; $M=$ total number of conventional generators; $N=$ total number of PV systems; $\alpha=$ minimum loading of the $i$ th conventional generator; $\mathrm{SOC}=$ battery bank state of charge; $t_{P_{g i}^{\min }}=$ minimum runtime of $i$ th conventional generator.

The economic dispatch problem has been solved using both the load following and cycle charging strategy controllers [11]. In both the strategies, the least cost optimal combination allows the dispatchable sources to generate and meet the load demand and reserve requirements. For calculating the cost, the fixed and marginal costs of the dispatchable sources have been considered.

\subsection{Techno-economic analysis and optimisation results}

Optimisation results calculated using HOMER, for both the scenarios are shown in Table 1 . Scenario-1 results have been obtained from the previous study and are presented here for a comparative analysis of both the scenarios. In scenario-2, as feeder A and B have similar characteristics and length, the results obtained for both feeders are identical. Feeder $\mathrm{C}$ serves more load. Hence, it is considered that feeder $\mathrm{C}$ can accommodate more $\mathrm{PV}$ capacity. The optimal design shows that a total of $374 \mathrm{~kW}$ of $\mathrm{PV}$ capacity is distributed among the three feeders as : $\mathrm{A}$ and $\mathrm{B}=100 \mathrm{~kW}$ each and $\mathrm{C}=174 \mathrm{~kW}$. The fuel savings potential is analysed for different SR strategies. SR is calculated as the summation of $10 \%$ of load and " $Z \%$ " of the $\mathrm{PV}$ generation for each time step. Here, " $Z$ ' is varied from $25 \%$ to $100 \%$ and the fuel savings potential ranges from $23.50 \%$ to $25.80 \%$. Scenario- 2 shows a reduction of $23.56 \%$ of $\mathrm{CO}_{x}$ emissions. The simulation considered the project life span to be 20 years and the cost of energy (COE) is calculated based on the net present cost (NPC) of the system. Comparing with the literature, this study yields quite similar results. For example, Peters et al. analysed cases (only with the PV) at $40 \%$ and $60 \%$ penetration*** with resulting fuel savings of $14.7 \%$ and $17.2 \%$, respectively. By adding a battery bank and keeping SR at $25 \%$ of $\mathrm{PV}$, the results are: for $40 \%$ (with $100 \mathrm{kWh}$ battery) and $60 \%$ (with $150 \mathrm{kWh}$ battery), PV penetration $-19.4 \%$ and $23.5 \%$, respectively [12].

\section{Technical investigation}

The second part of the analysis examines the technical issues of the system, based on the case designs for the scenarios. Significant technical challenges are associated with higher levels of PV penetration which have been depicted in Section 1. The dynamic behaviours of the system during transient conditions have been simulated using a balanced three phase RMS simulation (a time domain simulation for stability analysis) for $3 \mathrm{~min}$. A valid load flow initializes the simulation. Different functions govern the initial conditions of system elements including controller units and mechanical components. These initial conditions represent the steady-state operating point at the beginning of the simulation, fulfilling the requirements that the derivatives of all state variables of loads, machines and controllers are zero. 

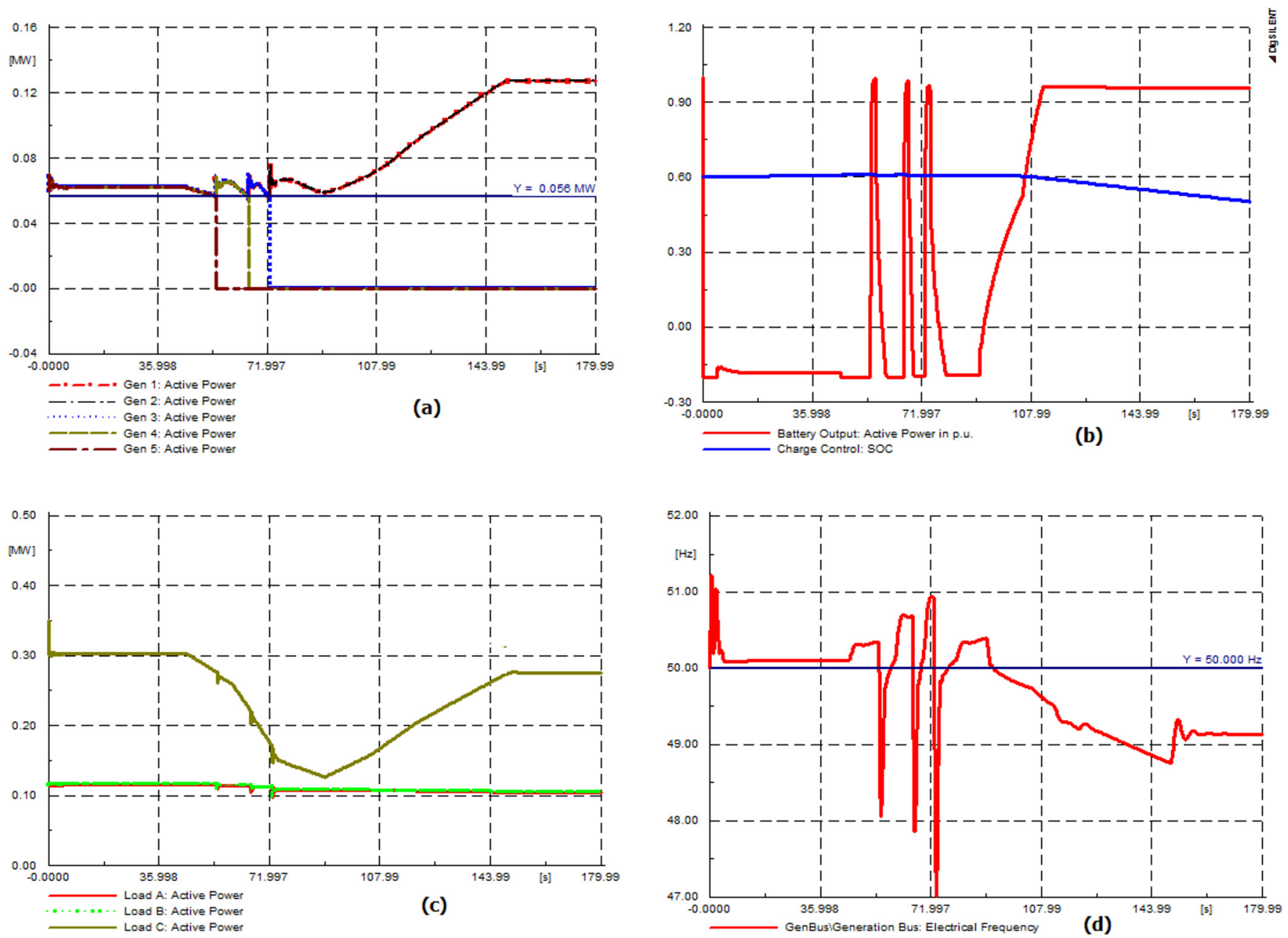

Fig. 4. Case 2 for scenario-1.
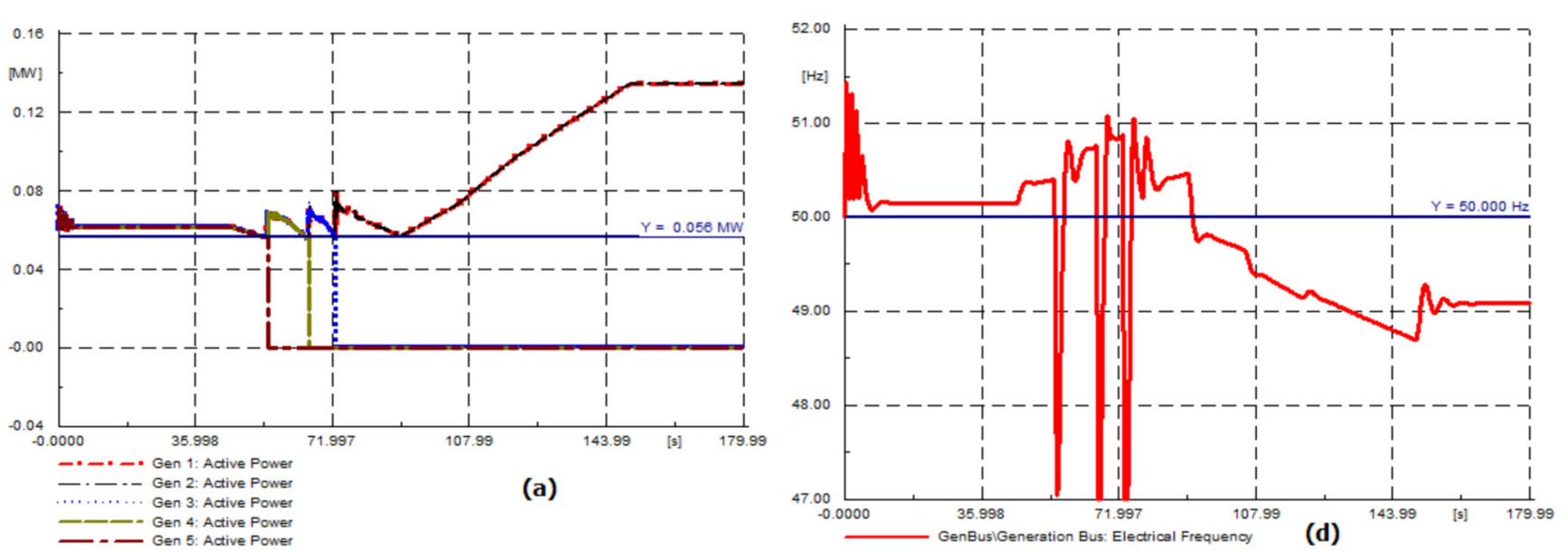

Fig. 5. Case 3 for scenario-1. 

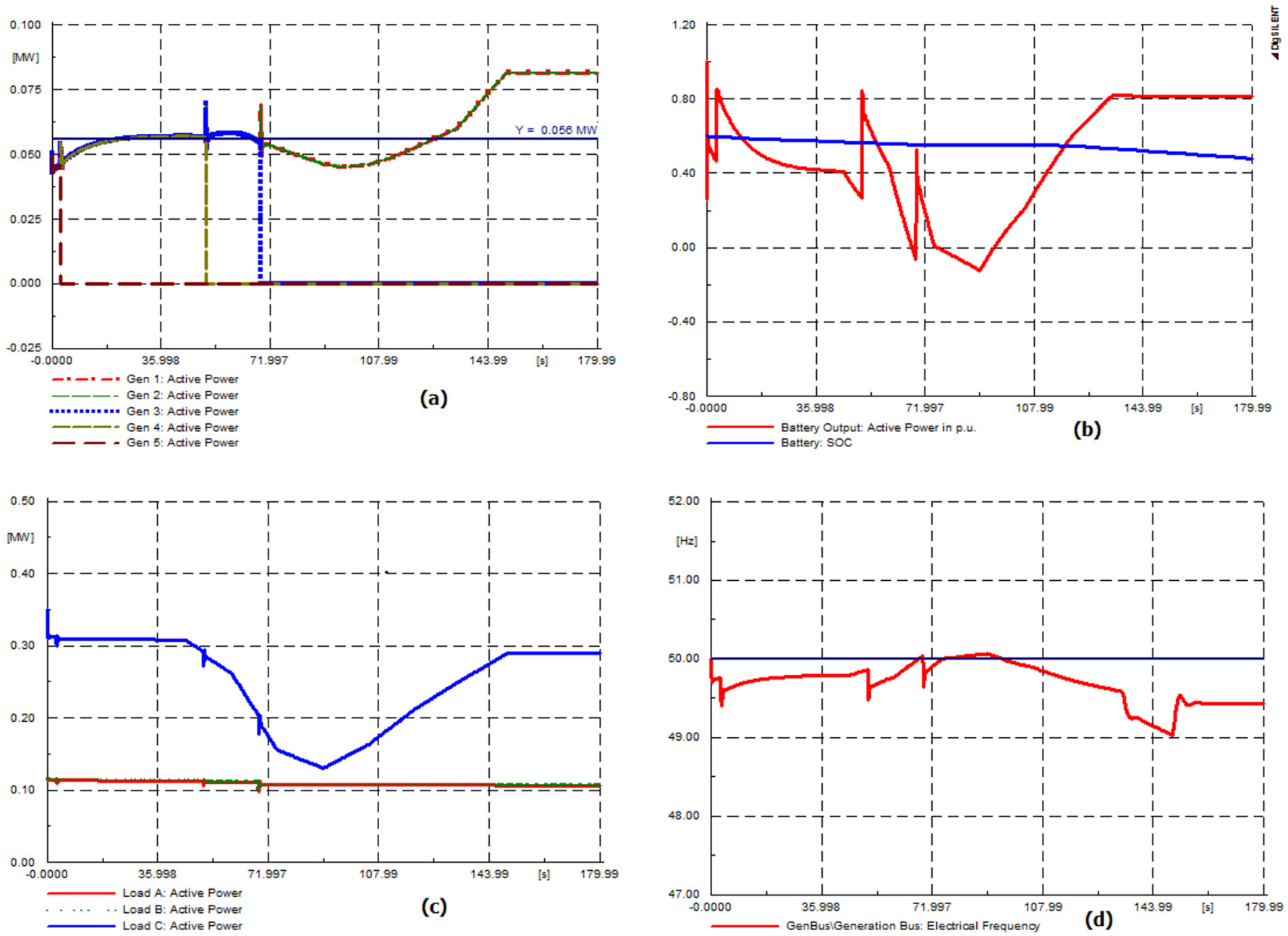

Fig. 6. Case 2 for scenario- 2 .
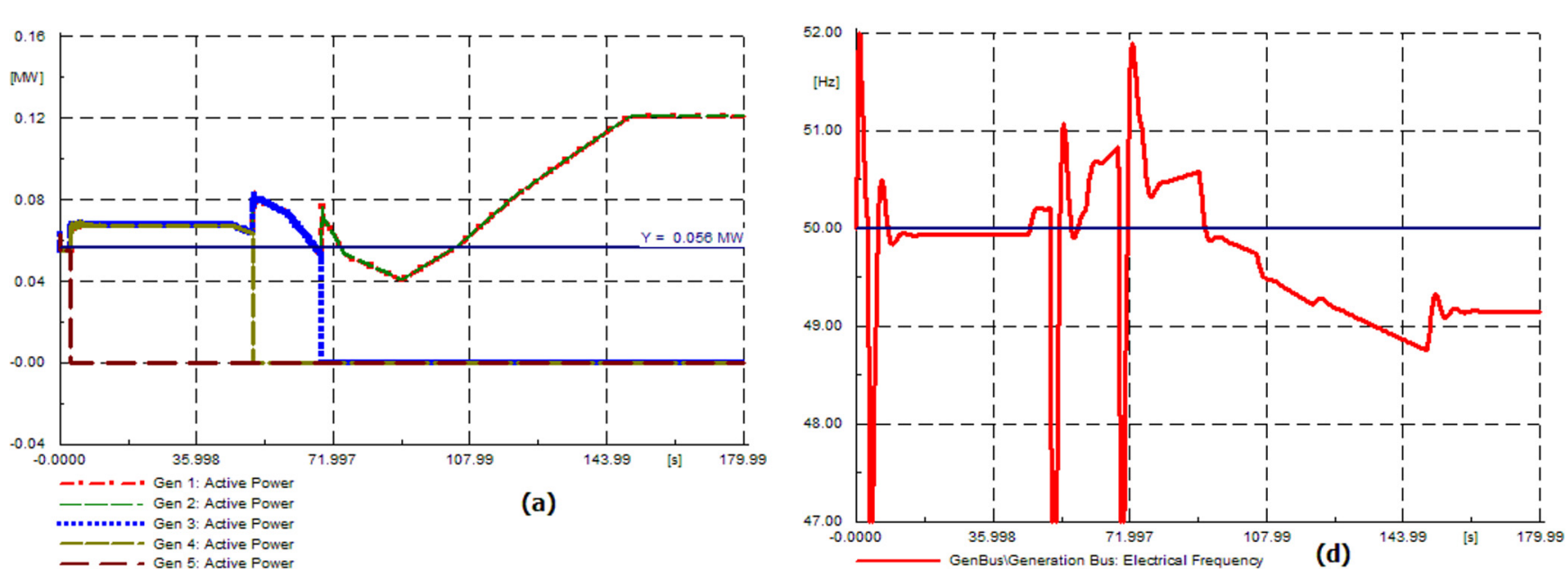

Fig. 7. Case 3 for scenario-2. 


\subsection{Case formulation}

Considering the best configuration for both the scenarios, a net load fluctuation profile has been used to simulate system dynamics (Fig. 3(c)). For better understanding, both scenarios are simulated based on three cases. The cases below have been designed to demonstrate the technical observations.

- Case 1: No. of Gen $=5, \mathrm{PV}=$ rated capacity, Battery $=$ rated capacity $^{1}$ and Load $=$ fluctuating.

- Case 2: No. of Gen=varies, PV = rated capacity ${ }^{1}$, Battery $=$ rated capacity $^{1}$ and Load $=$ fluctuating.

- Case 3: No. of Gen=varies, $\mathrm{PV}=$ rated capacity ${ }^{1}$, Battery $=$ nil and Load $=$ fluctuating.

\subsection{Observations and discussion}

Figures 3-7 illustrate the technical issues for both scenarios. Each figure presents the DGs' active power in MW (Fig: a), battery active power in per unit and SOC in \% (Fig: b), feeder loads ${ }^{2}$ in MW (Fig: c) and frequency of the generation bus in $\mathrm{Hz}$ (Fig: d). The system frequency is $50 \mathrm{~Hz}$. All the five DGs are sharing the load equally and are not allowed to run below the permitted $40 \%$ minimum loading $(56 \mathrm{~kW})$. The controller consists of frequency droop controller with droop setting of $5 \%$ for all DGs. The study does not include any integral and secondary controller to bring system frequency back to $50 \mathrm{~Hz}$ after dynamic events. The scenario- 1 (with $16 \mathrm{~kW}$ battery-inverter and $290 \mathrm{~kW}$ PV capacity) interactions for case- 1 are portrayed in Figure 3. When a net load decrement (maximum up to $57 \%$ ) occurs in feeder $\mathrm{C}$ either due to a sudden net load drop, all the five DGs are running below the permitted loading level during the disturbance period depicted in Figure 3(a). An over frequency event occurs and it exceeds the allowed upper limit for a period. The Li-ion battery bank is modelled as an FFR storage system, which responses to transient frequency fluctuation almost immediately. As long as the frequency stays above $50 \mathrm{~Hz}$, the battery bank continues to charge as a measure to increase the net load to reduce the frequency fluctuations. Once the frequency is back to $50 \mathrm{~Hz}$, the battery bank changes its charging status. When the generator busbar frequency drops below $50 \mathrm{~Hz}$, the battery bank starts discharging. Figure 4 represents the switching off of DGs and its impact on the system to alleviate the low loading issues of generators. Running at low load is an unwanted mode of operation for DGs, which hamper its internal mechanical components and affects lifespan. The low loading sensors take generators to the offline mode based on the pre-set priorities and network conditions e.g. ensuring enough combined reserve from online DGs and battery bank, to allow online generators to ramp up and run above the minimum loading limit. In Figure 4(a), DG nos. 5, 4 and 3 are shut down respectively in different timescales to help run the minimum number of generators above the minimum loading limit. At the 72nd second, when DG-3

\footnotetext{
${ }^{1}$ Rated capacity $=$ reference to Table 1.

${ }^{2}$ Load of feeders A, B and C are termed as Loads A, B and C, respectively in the figures.
}

is taken off the network, it is seen that the other 2 generators (DG-1 and DG-2) are taking the load and running above the $40 \%$ loading limit. The battery bank also responds to frequency oscillation and continues to discharge. The frequency is just above $49.10 \mathrm{~Hz}$ as the load becomes steady (Fig. 4(d)). Figure 5 shows the frequency dynamics without battery bank being present. As the battery bank inverter size is only $16 \mathrm{~kW}$ compared to load drop of $57 \%$ on feeder C, it does not offer much improvement in frequency response. Hence, increasing the battery bank and inverter size is suggested to alleviate substantial frequency fluctuation issues.

In scenario-2, a load fluctuation is applied to feeder C. Figures 6 and 7 present the cases 2 and 3, respectively. Responses from the DG disengagement and the $100 \mathrm{kWh}$ (Tab. 2) battery bank are shown in Figure 6(a) and (b), respectively. Comparing Figures 6 and Figures 6(d) and 7 (d), it is noticeable that the FFR battery bank plays a vital role to protect the network from substantial frequency fluctuation events.

These case analyses depict that an FFR Li-ion battery bank can facilitate the integration of higher levels of PV penetration, accompanying an abrupt high net load fluctuation in a remote PV-diesel system. In scenario-2, the $100 \mathrm{kWh}$ battery coupled with $200 \mathrm{~kW}$ inverter combats the substantial frequency excursion following a maximum of $57 \%$ of net load decrement. More controllable high power FFR battery/inverter capacity will help reduce frequency fluctuations. Voltage control and voltage stability study are beyond the scope of this study.

\section{Conclusion}

The analysis has attempted to investigate a remote Australian PV-diesel system to promote higher PV penetration. By studying the local climate and developing a computer-based simulation, a remote PV-diesel system optimisation and techno-economic analysis have been performed. From simulation studies; the system components, cost of energy, fuel usage, GHG emissions and PV penetration levels have been quantitatively analysed. A load flow analysis and time-domain RMS simulation have been performed on the optimised system to investigate system's dynamic behaviour during transient conditions. Any disturbance may arise from the PV variability characteristics and load dynamics which poses some technical challenges. This study shows that FFR battery storage reduces frequency fluctuations due to short-term load and PV power fluctuations. Future work will include simulations of the similar system incorporating robust controllers and various artificial intelligence options including PV forecasting to improve fossil fuel savings potential and further reduce system technical issues.

\section{References}

1. Horizon Power, Renewable Energy Buyback, Prices and Available Hosting Capacity (2016), Available from: http:// horizonpower.com.au/media/1592/buyback-prices-hostingcapacity-info-sheet_1_updated-march-2016.pdf 
2. S.K. Khadem, M. Basu, M.F. Conlon, Power quality in grid connected renewable energy systems: role of custom power devices, in International Conference on Renewable Energies and Power Quality (ICREPQ), Granada, Spain (2010)

3. S. Sayeef, T. Moore, S. Percy, D. Cornforth, J. Ward, D. Rowe, Characterisation and integration of high penetration solar power in Australia: a solar intermittency study, in 1st International Workshop on the Integration of Solar Power into Power Systems, Aarhus, Denmark (2011)

4. B. Enayati, Why Do We Need Standards Like IEEE 1547 ? (2016), Available from: http://smartgrid.ieee.org/newslet ters/october-2016/why-do-we-need-standards-like-ieee-1547

5. T. Jamal, T. Urmee, M. Calais, G.M. Shafiullah, C. Carter, Technical challenges of PV deployment into remote Australian electricity networks: a review, Renew. Sustain. Energy Rev. 77, 1309 (2017)

6. S. Sayeef, S. Heslop, D. Cornforth, T. Moore, S. Percy, J. Ward et al., Solar Intermittency: Australia's Clean Energy Challenge - Characterising the Effect of High Penetration Solar Intermittency on Australian Electricity Networks (CSIRO, 2012)
7. T. Jamal, M.A. Shoeb, G. Shafiullah, C.E. Carter, T. Urmee, A design consideration for solar PV-diesel remote electricity network: Australia perspective, in IEEE PES Innovative Smart Grid Technologies (ISGT)-Asia 2016, Melbourne, Australia (2016)

8. Power and Water Corporation, Solar/Diesel Mini-Grid Handbook (Australia, 2014)

9. CAT Projects and ARENA, Investigating the Impact of Solar Variability on Grid Stability (2015)

10. HOMER Energy, Microgrid Decisions Made with Confidence (2017), Available from: http://www.homerenergy.com/in dex.html

11. T. Lambert, P. Gilman, P. Lilienthal, Micropower system modeling with HOMER, in Integration of Alternative Sources of Energy, edited by F.A. Farret, M.G. Simoes (John Wiley \& Sons, Inc., 2005)

12. D. Peters, T. Kilper, T. Jamal, M. Calais, K.V. Maydell, Solar short-term forecasts for predictive control of battery storage capacities in remote PV diesel networks, in World Renewable Energy Congress XVI, Perth, Australia (2017)

Cite this article as: Taskin Jamal, G.M. Shafiullah, Craig Carter, Tania Urmee, A comprehensive techno-economic and power quality analysis of a remote PV-diesel system in Australia, Renew. Energy Environ. Sustain. 2, 24 (2017) 